\title{
Mixing Study in an Unbaffled Stirred Precipitator Using LES Modelling
}

\author{
Murielle Bertrand, ${ }^{1}$ Delphine Parmentier, ${ }^{1}$ Olivier Lebaigue, ${ }^{2}$ \\ Edouard Plasari, ${ }^{3}$ and Frédéric Ducros ${ }^{2}$
${ }^{1}$ Nuclear Energy Division, Radiochemistry and Processes Department, French Alternative Energies and Atomic Energy Commission, 30207 Bagnols sur Ceze, France
${ }^{2}$ Nuclear Energy Division, Reactor Studies Department, French Alternative Energies and Atomic Energy Commission, 34054 Grenoble, France
${ }^{3}$ Reactions and Process Engineering Laboratory, CNRS, 54001 Nancy, France

Correspondence should be addressed to Murielle Bertrand, murielle.bertrand@cea.fr

Received 9 December 2011; Revised 8 March 2012; Accepted 14 March 2012

Academic Editor: Nandkishor Nere

Copyright (C) 2012 Murielle Bertrand et al. This is an open access article distributed under the Creative Commons Attribution License, which permits unrestricted use, distribution, and reproduction in any medium, provided the original work is properly cited.

\begin{abstract}
This paper describes the CFD modelling of a reactor operating in the nuclear industry using LES approach. The reactor consists of an unbaffled stirred tank reactor in which plutonium precipitation reactions are carried out. The flow generated in such a precipitator is complex and there is very little information available in the literature about unbaffled reactors stirred with magnetic rod. That is why a hydrodynamic modelling has been developed using computational fluid dynamics (CFD) in order to get accurate description of mixing phenomena inside the precipitator and therefore to be able to predict the solid particle properties. Due to the strong turbulence anisotropy, the turbulence transport simulation is achieved by a large eddy simulation (LES) approach which gives unsteady solutions. The numerical simulations are performed in 3D using the Trio_U code developed at the Commissariat à l'Énergie Atomique. The predictive performances of the modelling are analysed through a mixing phenomena study. Both experimental and numerical studies are performed. This work shows how hydrodynamics inside the reactor can have a noticeable effect on the precipitate properties and how LES modelling is a very effective tool for the process control.
\end{abstract}

\section{Introduction}

Owing to the manipulation of radioactive materials at large scale, nuclear industry has to implement reactors with unusual design. An unbaffled magnetic rod-stirred reactor thus has been developed in the spent nuclear fuel reprocessing industry for use as a precipitator $[1,2]$. Precipitation reactions being very fast are well known to be highly sensitive to mixing effects. That is why an accurate knowledge of the hydrodynamics inside the reactor is particularly essential to control the quality of the solid particles formed, on the one hand, and to develop a global modelling of the precipitation process, on the other hand.

Flows in stirred unbaffled vessels have not been widely discussed in the literature, unlike stirred baffled vessels, because they are less frequently used in processes [2-4]. Their mixing performance is significantly lower due to the predominance of the tangential velocity over the axial and radial velocity components. Without counterimpellers, however, fluid rotation leads to the formation of a vortex that distorts the free surface; some applications can take advantage of this vortex. In the precipitator considered here, this configuration limits scaling by maintaining potentially adhering particles away from the walls and thus facilitates maintenance procedures that are particularly demanding in nuclear industry.

Moreover, all the studies described in the literature concern conventional impellers, either radial (turbines, flator pitched-blade stirrers) or axial (helical impellers), none of which corresponds to a magnetic rod rotating at the bottom of the vessel.

According to Rankine's combined vortex description, the hydrodynamics in an unbaffled reactor is characterized by the presence of two macromixing zones. The liquid near 
the axis rotates as a solid cylinder with an angular velocity closed to the agitator one, whereas the outside liquid behaves as a free vortex [5]. The presence of these two different mixing zones highly impacts the distribution of reagent concentrations and the powder quality.

Knowing how important it is to entirely control the properties of actinide precipitates, a hydrodynamic modelling of the vortex precipitator has been undertaken using computational fluid dynamics (CFD). Due to the predominance of the circulation flow around the impeller axis, the turbulence is highly anisotropic. Then, the classical statistical turbulence models (Reynolds-Average-Navier-Stokes(RANS-) like models) cannot be applied. The turbulence transport simulation can be achieved using the Large Eddy Simulation (LES) approach which resolves the largest scales using filter and gives the unsteady flow field taking into account the real movement of the stirrer. LES appears to be a very promising alternative to RANS techniques and direct numerical simulations (DNSs) [6-8]. The first ones present many limitations especially when solving complex flows with highly anisotropic turbulence while the latter one remains still far too expensive for industrial applications. Recently several chemical engineering studies based on the large eddy simulation approach have been published in the literature, to describe flows in baffled and unbaffled stirred tank reactor [9-13]. Results obtained are overall very satisfactory.

The objective of this work is to check the potential of LES approach to describe mixing in the vortex reactor and then to be applied to model the precipitation process.

\section{Precipitation Experiments}

2.1. Experimental Setup. In order to highlight the influence of the presence of two macromixing zones on the precipitation mechanisms, different reagent feeding positions are tested in the vortex reactor. Due to obvious experimental constraints, experiments are performed using neodymium to simulate the actinide behaviour [14] at laboratory scale in a geometric similarity reactor, shown in Figure 1. It consists of an unbaffled glass cylindrical vessel stirred by a cylindrical magnetic rod and equipped with a thermostated loop and an overflow nozzle.

The ratios between the tank diameter $T$, the tank height $H$, and the rod length $D$ are as follows:

$$
\begin{gathered}
\frac{D}{T}=0.47, \\
\frac{H}{T}=1.5 .
\end{gathered}
$$

The precipitations are carried out at room temperature by mixing continuously a neodymium III nitrate solution to an oxalic acid solution, according to the following equilibrium:

$$
\begin{aligned}
2 \mathrm{Nd}\left(\mathrm{NO}_{3}\right)_{3}+3 \mathrm{H}_{2} \mathrm{C}_{2} \mathrm{O}_{4} \stackrel{\mathrm{H}_{2} \mathrm{O}}{\longrightarrow} & \mathrm{Nd}_{2}\left(\mathrm{C}_{2} \mathrm{O}_{4}\right)_{3} \cdot 10 \mathrm{H}_{2} \mathrm{O} \\
& +6 \mathrm{HNO}_{3}
\end{aligned}
$$

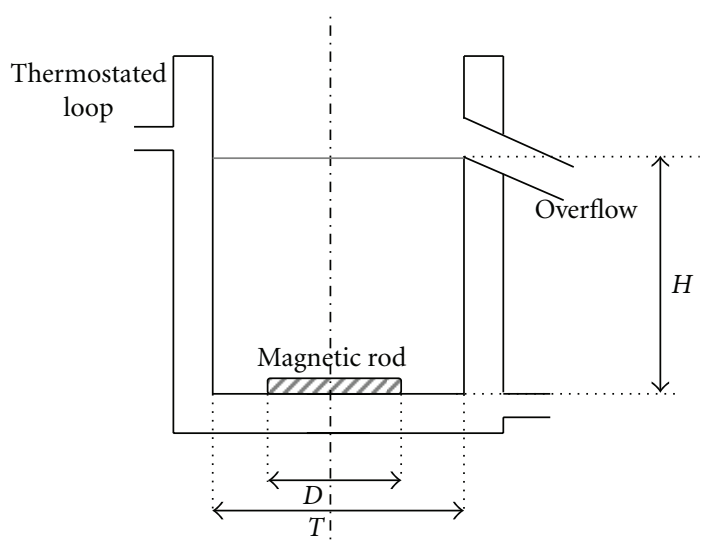

FIgURE 1: Experimental precipitator diagram.

TABLE 1: Operating parameters of precipitation experiments.

\begin{tabular}{lc}
\hline Temperature $T\left({ }^{\circ} \mathrm{C}\right)$ & 25 \\
Residence time $\tau) \min )$ & 30 \\
{$\left[\mathrm{Nd}^{3+}\right]\left(\mathrm{mol}^{-1}\right)$} & 0.2 \\
{$\left[\mathrm{C}_{2} \mathrm{O}_{4}{ }^{2-}\right]\left(\right.$ mol. $\left.\mathrm{L}^{-1}\right)$} & 0.7 \\
$\begin{array}{l}\text { Acidity in the reactor } \\
\left(\text { mol. } \mathrm{L}^{-1}\right)\end{array}$ & 1 \\
\hline
\end{tabular}

They are performed under stoichiometric conditions and in nitric acid medium.

The rotation speed is adjusted so that the volume power consumption is the same one as for the industrial feature. The flow is fully turbulent as the impeller Reynolds number is greater than $10^{4}[15]$ :

$$
\operatorname{Re}_{a}=\frac{N D^{2}}{v} \approx 210^{4}
$$

where $N$ is the stirrer speed and $v$ the kinematic viscosity.

Precipitation experimental conditions are detailed in Table 1.

Samples taken at the reactor outlet are analyzed using a particle size analyzer (Malvern Mastersizer) and observed by scanning electron microscopy (SEM).

Two feeding point positions are investigated as shown in Figure 2: one located into the free vortex (a) and the other located into the forced vortex (b). The reagents are injected above the surface of the liquid.

2.2. Experimental Results. Experimental results point out a sensible influence of the feeding location on the crystal size. Figure 3 shows the SEM photos of neodymium III oxalate which has a lengthened platelets shape and Table 2 compares the mean particle sizes which vary by a factor of 1.5 to 2 . Larger crystals are obtained when the reagents are injected into the free vortex.

2.3. Mixing Phenomena Observations. These two operating conditions lead to different hydrodynamic behaviours of the system. In the first case, the precipitate appears into 


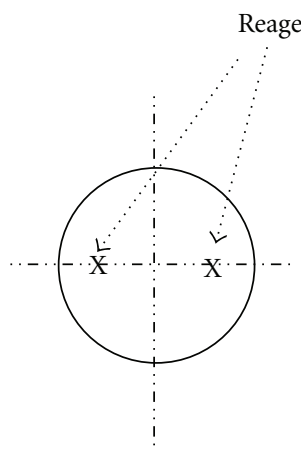

(a) In the free vortex
Reagent feeding points

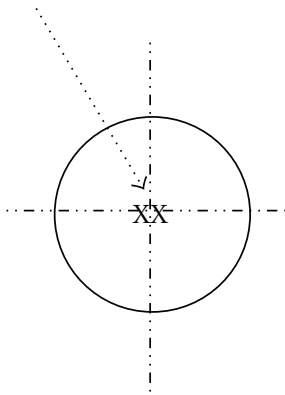

(b) In the forced vortex

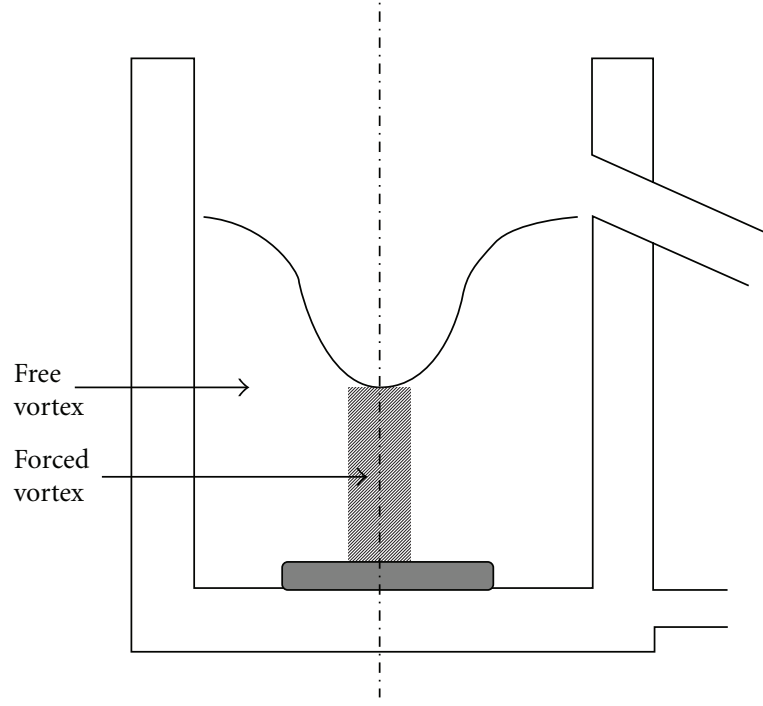

FIGURE 2: Feeding positions in the precipitator.

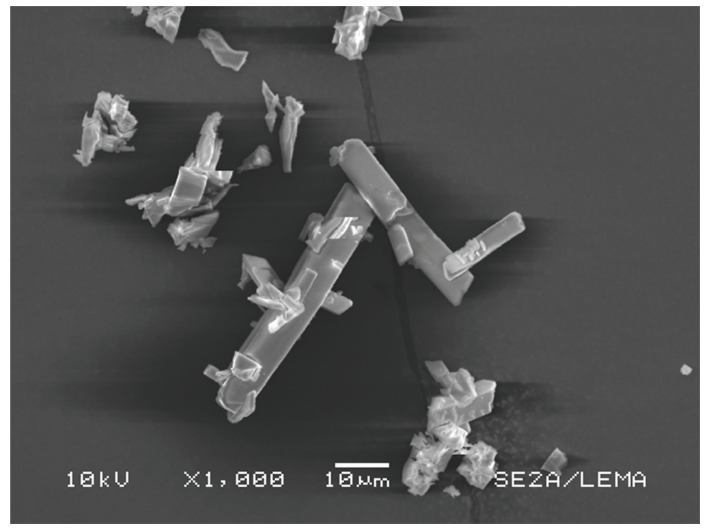

(a)

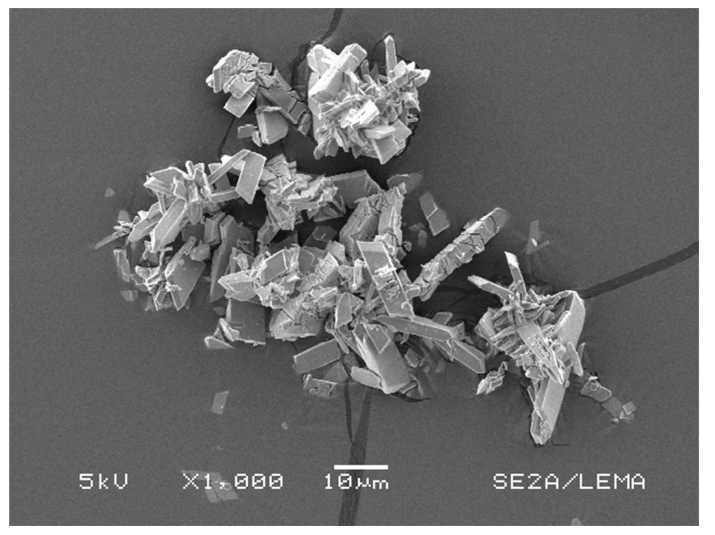

(b)

FIGURE 3: Neodynium III oxalate crystals obtained in the free vortex (a) and in the forced vortex (b).

TABle 2: Mean volume crystal size depending on the feeding position.

\begin{tabular}{lc}
\hline Feeding point localisation & $L_{43}(\mu \mathrm{m})$ \\
\hline Forced vortex & $80-100$ \\
Free vortex & $160-180$ \\
\hline
\end{tabular}

the whole of the reactor as shown in Figure 4(a). On the contrary, for a reagent inlet located into the forced vortex, a coloured column appears at the reactor centre (see Figure 4(b)), and then the precipitate diffuses progressively inside the free vortex from the reactor bottom upwards.

This experimental study proves the major role of flows which characterise an unbaffled precipitator and points out the need for an accurate hydrodynamic description in order to quantify this influence and to guarantee a better control of the process. That is why the flow pattern inside the precipitator is studied using computational fluid dynamics (CFD).

\section{Hydrodynamic Modelling}

Unbaffled reactors are characterised by a strong turbulent anisotropy as the tangential component is largely predominant. The turbulence models based on the eddy viscosity concept ( $k$ - $\varepsilon$-like models), classically used in chemical engineering, cannot take into account the turbulence anisotropy. That is why a hydrodynamic modelling has been developed at industrial scale using the large eddy simulation (LES) approach which gives unsteady solutions. In LES approach, the large scales are solved while the small ones are modelled by applying a space filter [16] so that the unsteady flow field can be reached according the real movement of the magnetic rod. The numerical simulations are performed in 3D with the trio_U code developed at the French Atomic Energy Commission [17-20].

3.1. Calculation Parameters. The computational field is based on the geometry shown in Figure 1. Inlet and outlet 


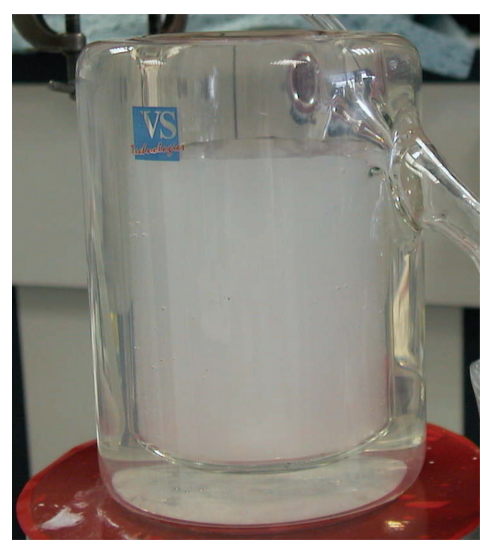

(a) In the free vortex

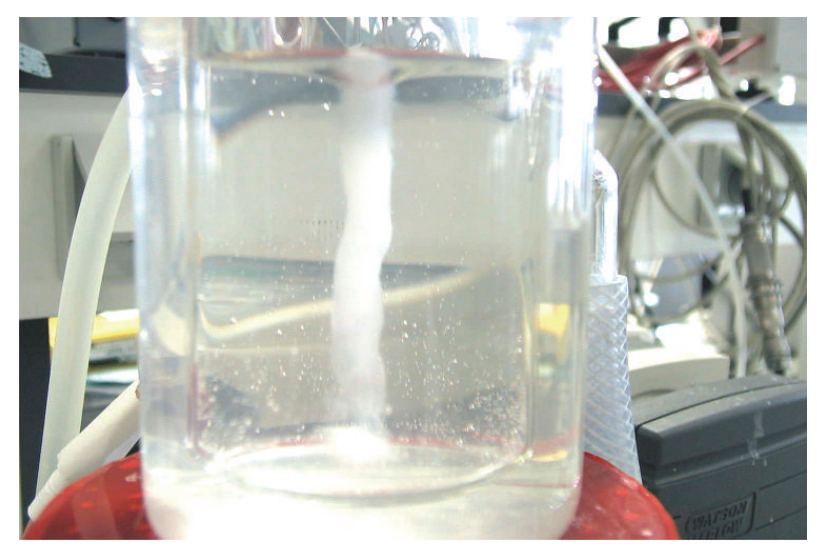

(b) In the forced vortex

FIGURE 4: Reagent feeding position influence during the precipitation process.

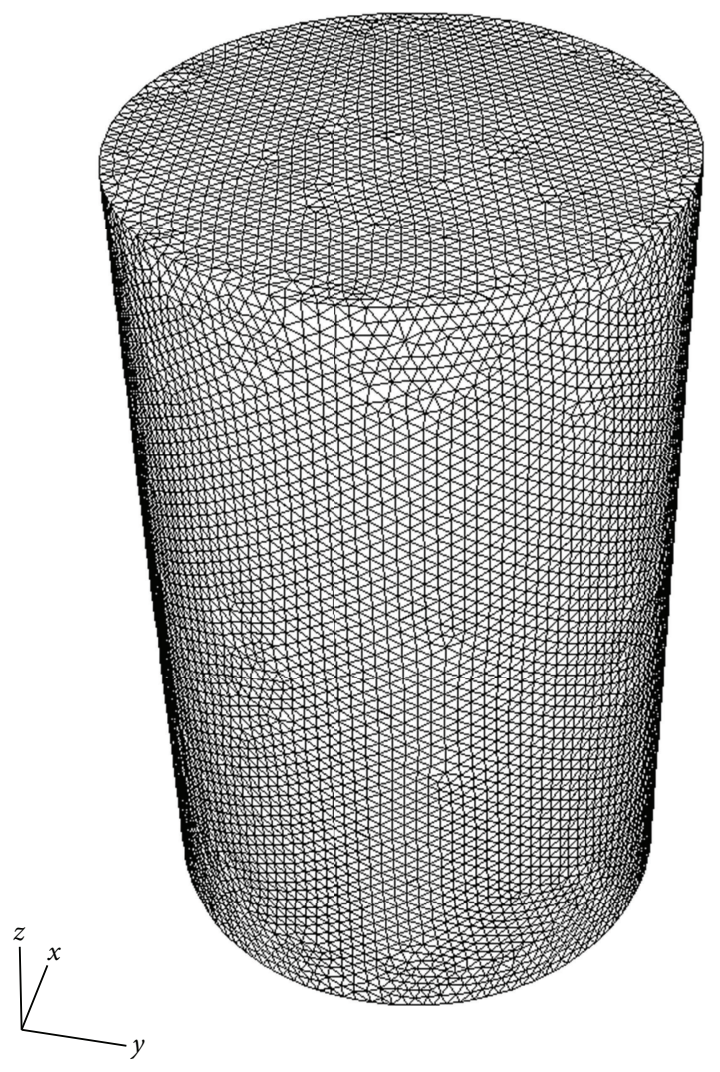

FIGURE 5: Homogeneous unstructured grid with tetrahedral elements.

flows are not taken into account. A fixed homogeneous unstructured grid is realised with about 650000 tetrahedral elements of approximately the same volume (see Figures 5 and 6).

The ratio between the cell length scale $\Delta x$ and the tank diameter $T$ is about $\Delta x=T / 40$. The ratio of cell volume to mean cell volume ranges from 0.101 and 3.16. The histogram of the largest angle of each tetrahedral element (see Figure 6) shows the good quality of the mesh.

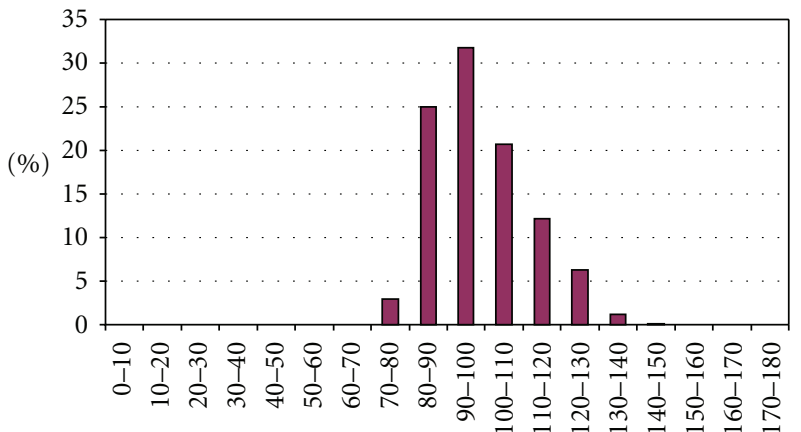

(deg)

FIgURE 6: Histogram of the largest angle of tetrahedra.

The tank is supposed to be filled with water. The initial conditions of this calculation consider a fluid at rest with a horizontal free surface. At the initial instant the magnetic rod is driven to the required constant rotation speed with a Reynolds number of about $710^{4}$.

The air/water interface is simulated by the Discontinuous Front Tracking method [21] and defined by a moving Lagrangian mesh independent of the Eulerian finite element mesh of the computational field. This two-phase gas/liquid model presents the advantage of simulating the free surface motion according to the flow.

The magnetic rod is taken into account by an Immersed Boundary Condition model [22]. It is defined by an independent Lagrangian mesh which rotates at an imposed constant speed [23] and its action on the surrounding fluid results in additional momentum source terms (forcing terms). NavierStokes equations are then solved in the fixed frame of the tank.

Characterised by an impeller Reynolds number equal to $710^{4}$, the flow is fully turbulent.

The eddy viscosity is modelled according to the Wall-Adaptating Local Eddy-Viscosity concept (the WALE model) [24]. This subgrid turbulence model, which is a functional-modelling-like unsteady model, improves the system behaviour near walls, in shear layers, and in turbulence transition process. 


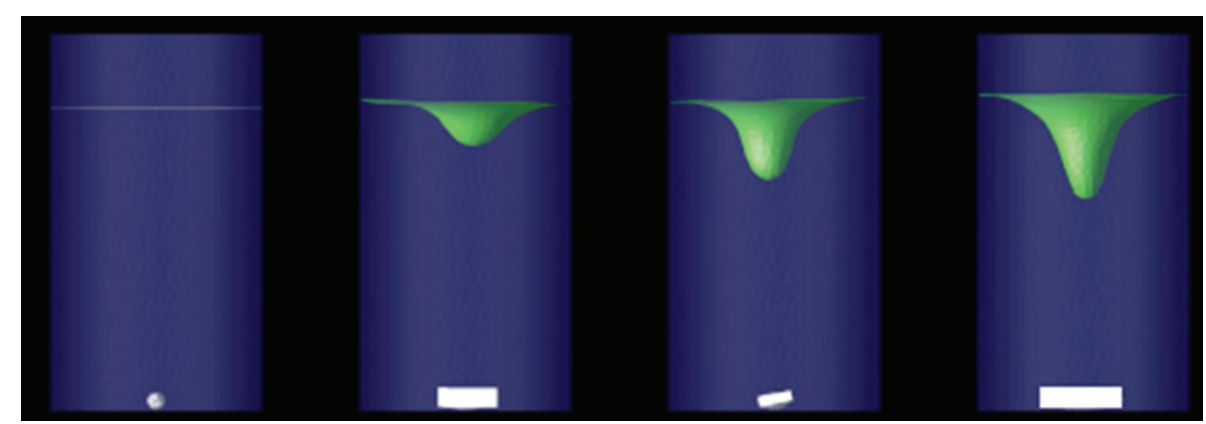

FIgURE 7: Vortex formation after stirrer startup.

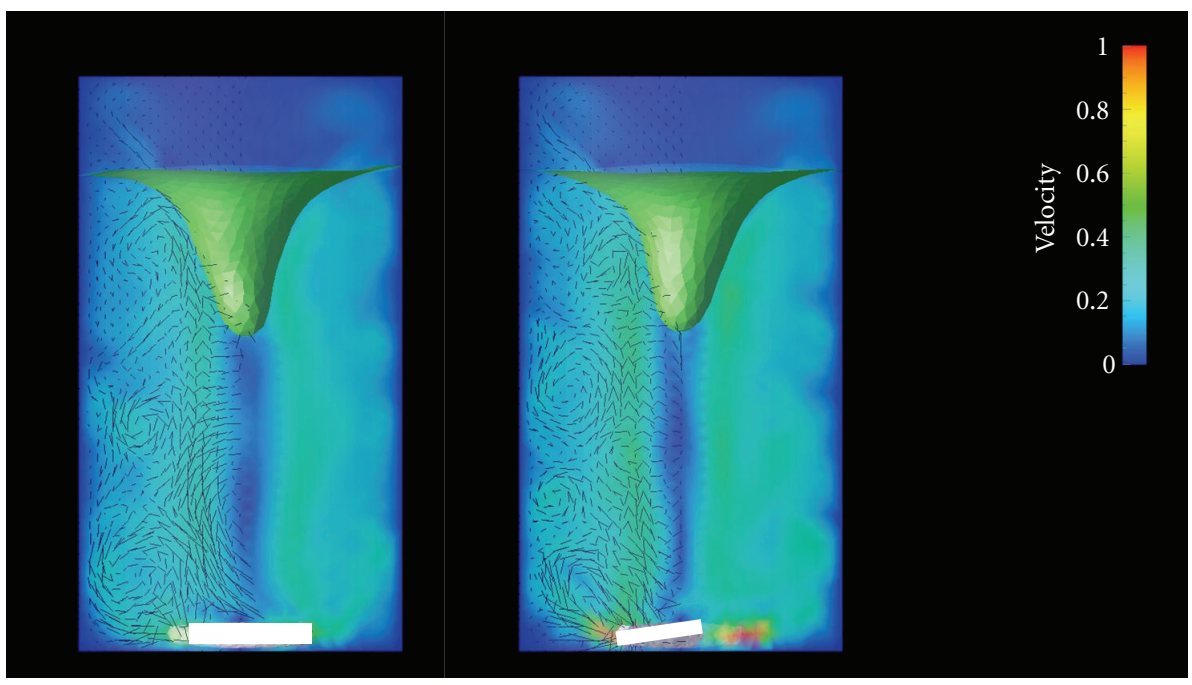

FIGURE 8: Vector velocity field at two different rod positions on a reactor midplane.

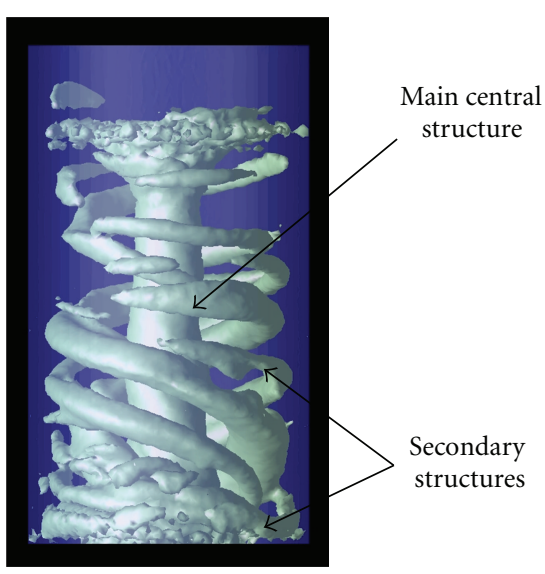

FIGURE 9: Representation of instantaneous turbulent flow structures using $Q$ criterion.

The top of the tank is an open boundary with an imposed pressure. The walls are modelled with standard law-ofthe-wall boundary conditions, as boundary layers are not resolved by the mesh.
3.2. Inducing Fluid Flow. The stirring action at the bottom of the vessel imparts a rotating movement to the fluid and forms a vortex at the surface. The entire fluid volume cannot be placed in movement instantaneously: 15 seconds are necessary for the volume fluid to reach steady-state kinetic energy conditions. Figure 7 shows this progressive vortex formation following the stirrer startup.

The unsteady gas/liquid interface simulation method allows us to observe the continuous movement of the free surface after formation of the vortex, unlike statistical approaches that give the time averaged fields and then cannot capture the time fluctuations [2]. The vortex follows the main rotational movement of the flow, and the interface is therefore not exactly axisymmetric in the vortex zone: its tip exhibits slight processional motion with a vertical.

3.3. LES Instantaneous Velocities. In agreement with Nagata's model [25], the main flow comprises fluid rotation around the vessel symmetry axis, in which the tangential velocity component predominates. However, the tangential velocity norm varies in space and time with the rod position. The fluid is periodically discharged radially by the rod, forming swirling structures superimposed on one other over the full height of the reactor. These moving structures 


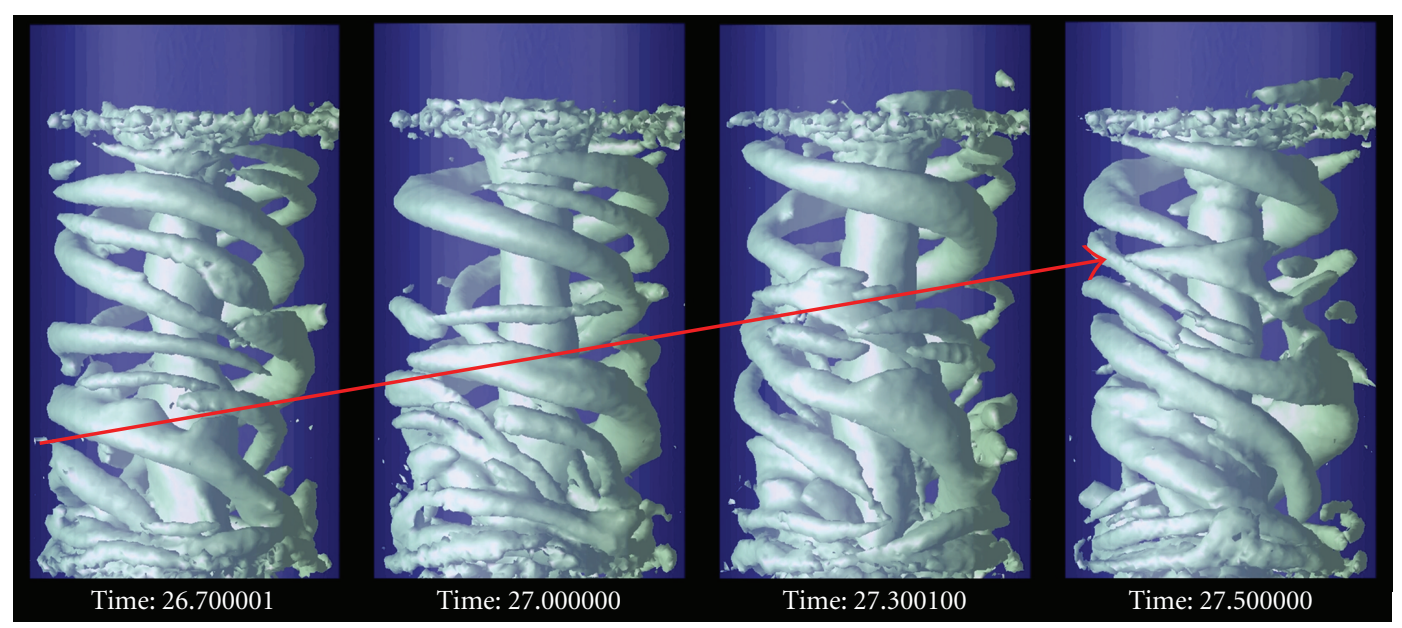

FIGURE 10: Upwards movement of the secondary structures.

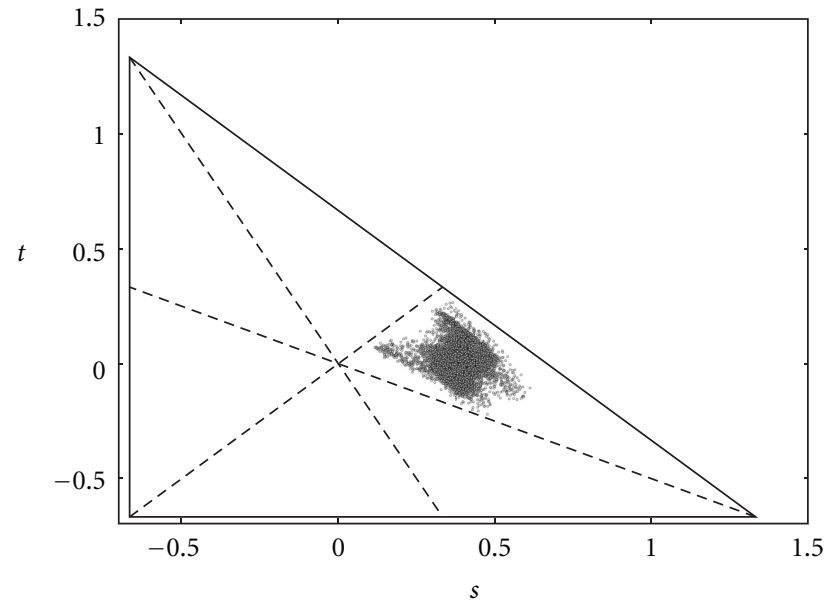

(a)

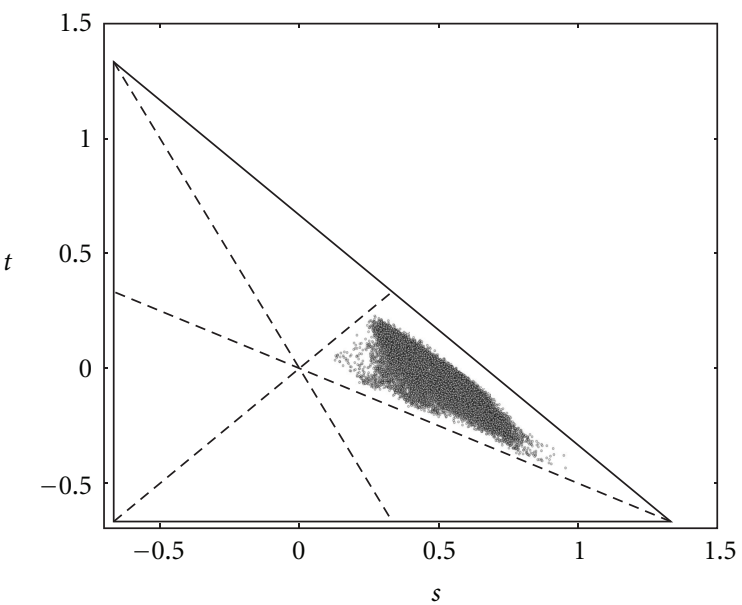

(b)

FIGURE 11: Values of $(s, t)$ in the Lumley triangle for the forced (a) and the free vortex zone (b).

TABLE 3: Comparison of CFD $r_{c}^{*}$ value with Nagata's and Le Lan's models $\left(\operatorname{Re}_{a}=710^{4}\right)$.

\begin{tabular}{cccc}
\hline & LES & Nagata's correlation & Le Lan's correlation \\
\hline$r_{c}^{*}$ & 0.5 & 0.53 & 0.51 \\
\hline
\end{tabular}

of smaller magnitude vary approximately synchronously with the movement of the stirrer. The velocity vector field shown in Figure 8 on a reactor mid-plane at different times demonstrates the displacement of these structures.

The turbulent structures can be observed using the levelsets of the $Q$ criterion which is the commonly used Eulerian criteria for coherent vortices [26]. Representing the eddy structures based on this turbulence criterion shows a dominant vertical central structure (see Figure 9) surrounded by smaller secondary structures that exhibit not only helical rotational movement around the vessel centreline but also upward motion from the bottom toward the vortex (see
Figure 10). The secondary structures are in the free vortex zone.

As LES solution holds most of the turbulent fluctuations (those solved by the grid), it is possible to have access in each control volume to good estimates of Reynolds tensor and then to build the Lumley triangle [27]. The $(s, t)$ values in the Lumley triangle, obtained in the forced and in the free vortex zones, are shown in Figure 11 ( $s$ and $t$ are the first and second eigenvalues of the anisotropy tensor [27]). They clearly highlight the strong turbulence anisotropy in most of regions of the precipitator, as no dots are situated close to the origin.

3.4. Comparison with Experimental Results. Experimental velocity measurements have been performed in the vortex reactor using Laser Doppler Velocimetry. Figure 12 provides a comparison between the tangential, radial, and axial velocities measured experimentally and calculated with LES. Velocities are dimensionalized using a reference velocity $V_{\theta}=\pi N D$ and their evolution is given with respect to the 


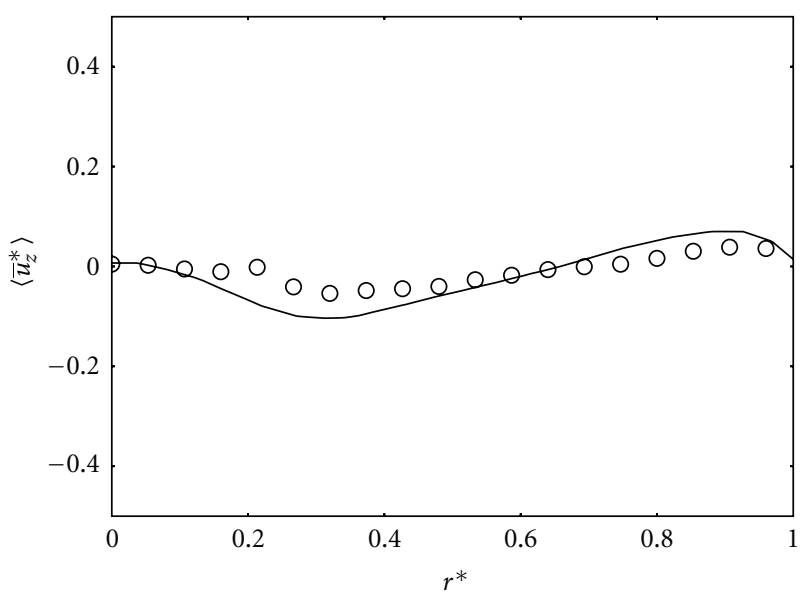

(a)

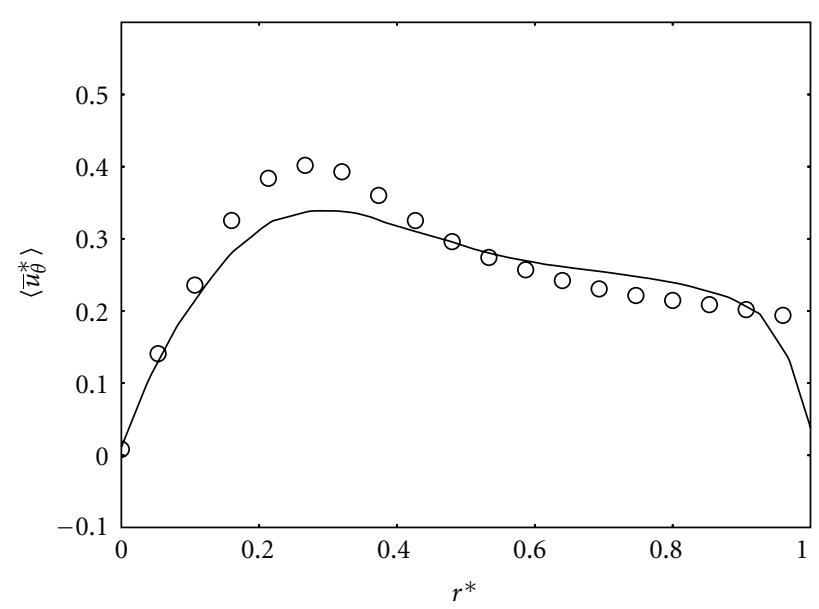

(c)

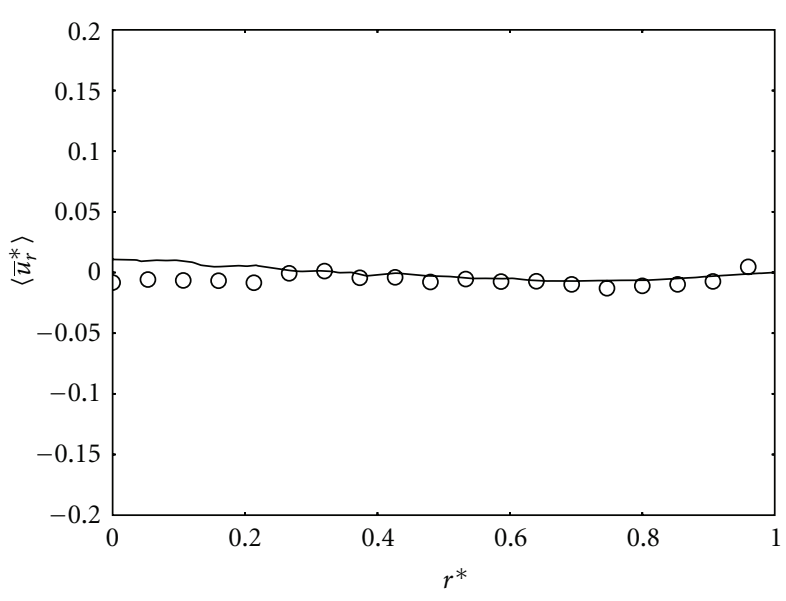

(e)

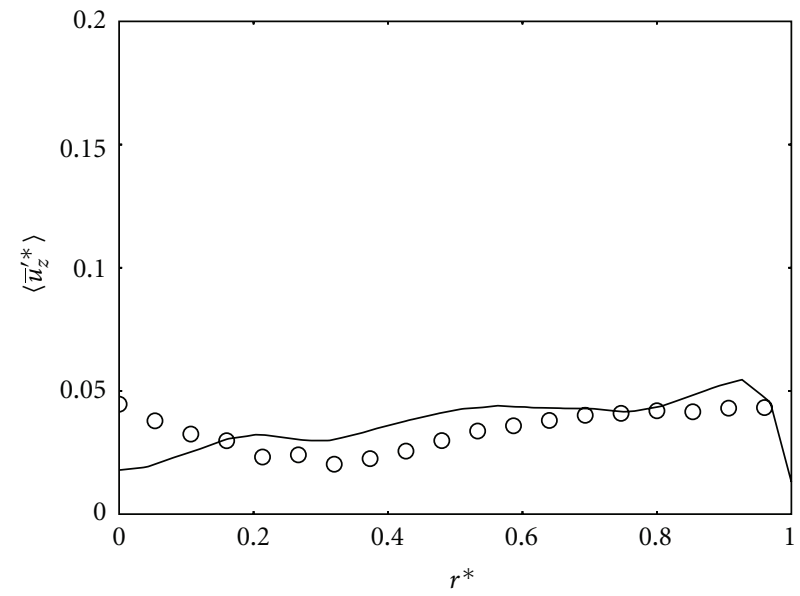

(b)

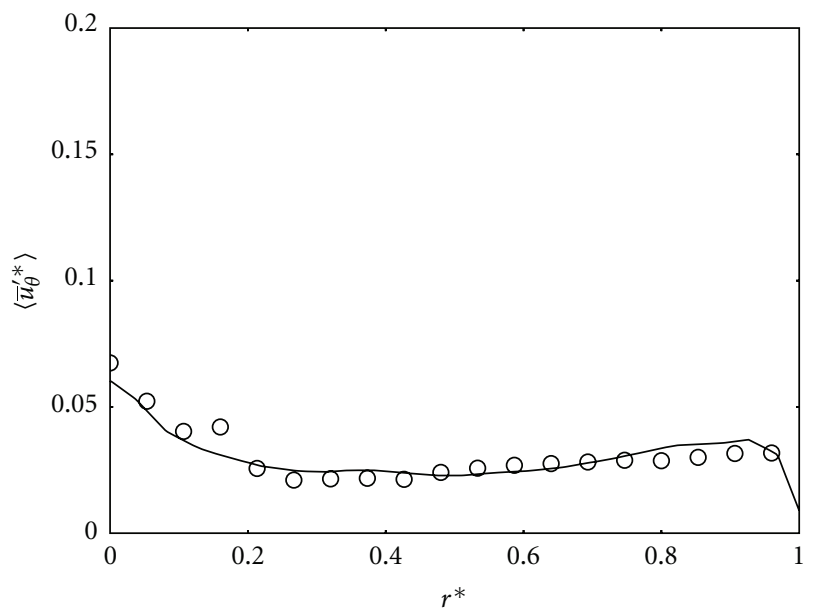

(d)

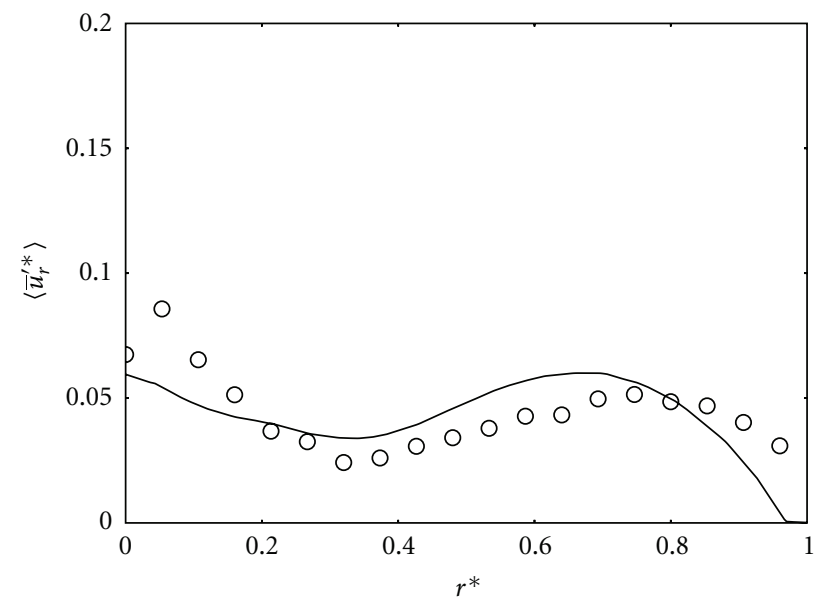

(f)

FIGURE 12: Mean $(\bar{u})$ and fluctuating parts $\left(u^{\prime}\right)$ of the velocity field along the radius at the same height $z^{*}=0.35$. Solid lines: LES results; symbols: experiments. 


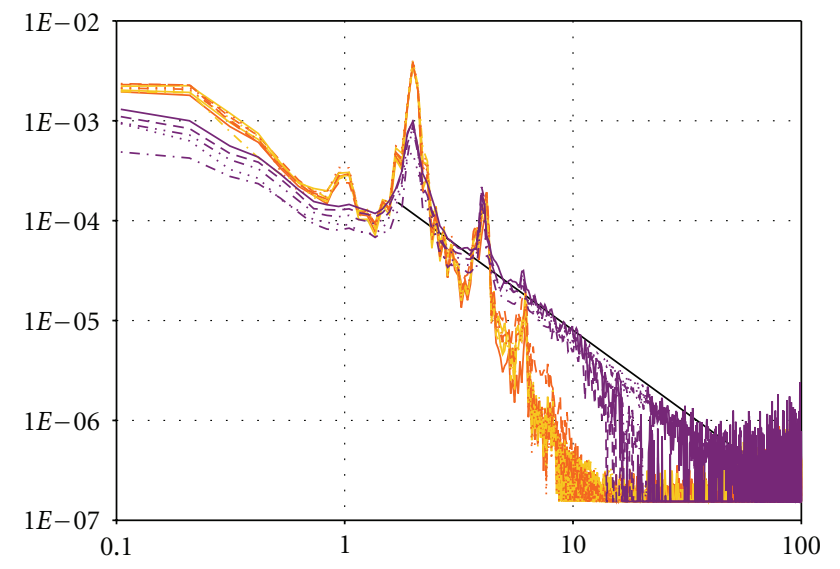

FIGURE 13: Energy spectrum of the vertical velocity fluctuations in the forced vortex $\left(z^{*}=0.11\right.$ and $\left.r^{*}=0.18\right)$. Violet line: experiments (measured at $0,90,180$, and $270^{\circ}$ at the same $z^{*}$ and $r^{*}$ ); orange lines: LES computations (measured at $0,45,90, \ldots$, $315^{\circ}$ ) at the same $z^{*}$ and $\left.r^{*}\right)$. The black straight line is a $k^{-5 / 3}$ slope.

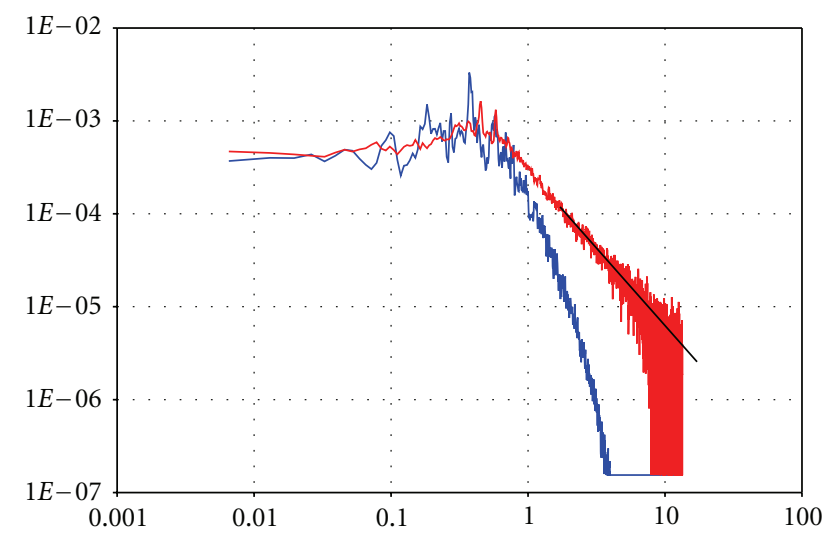

FIGURE 14: Energy spectrum of the radial velocity fluctuations in the free vortex $\left(z^{*}=0.35\right.$ and $\left.r^{*}=0.89\right)$. Red line: experiments; blue lines: LES computations. The black straight line is a $k^{-5 / 3}$ slope.

nondimensionalized radius $r^{*}$ for the height $z^{*}=Z / H=$ 0.35 :

$$
\begin{gathered}
u_{i}^{*}=\frac{u_{i}}{\pi N D}, \\
r^{*}=\frac{2 r}{D} .
\end{gathered}
$$

where $u$ is the velocity vector and $r$ the radial distance.

We can notice that fluctuations are very intense for all components, especially at the bottom of the tank (See Figure 12). Mean and fluctuating axial velocity are of the same order. Moreover, radial fluctuations are much stronger than the mean counterparts (with the very exception of the region close to the impeller). This indicates a strong unsteadiness of the flow. Additional comparisons, at different heights can be found in a previous publication [28] which shows that most of the mean and fluctuating velocities are well described by our LES simulation.

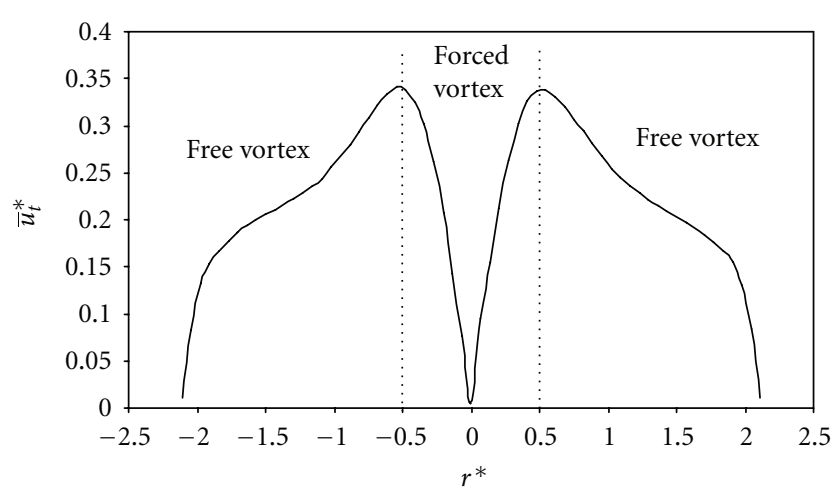

FIGURE 15: Computational mean tangential velocity profile.

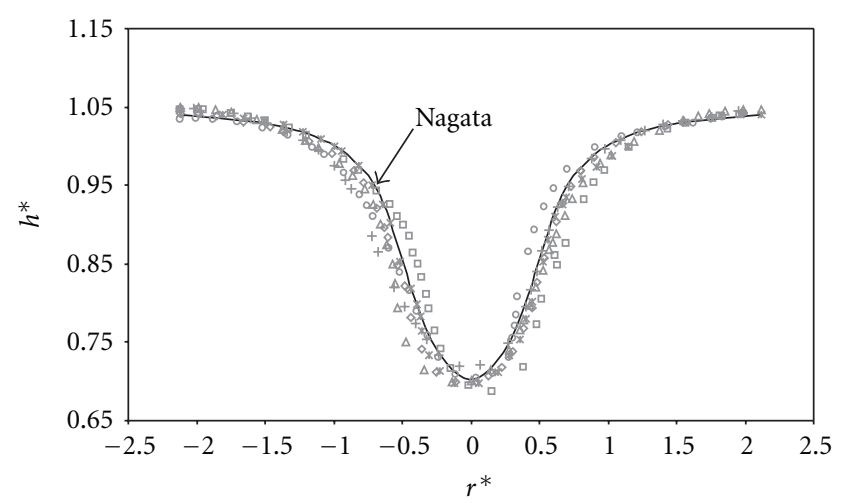

FIGURE 16: Comparison between computational vortex profiles (points) and Nagata's theory (black line).

A more detailed analysis of the flow inside the vortex reactor can be provided by a spectral analysis. In order to be compared with experimental results, spectra are computed from temporal signals whose duration exceeds $7000 \mathrm{rod}$ rotations for experimental signals and 200 rod rotations for LES computations.

Figure 13 shows a typical spectrum of the vertical velocity fluctuations in the forced vortex region $\left(z^{*}=0.11\right.$ and $\left.r^{*}=0.18\right)$ and Figure 14 in the free vortex region $\left(z^{*}=\right.$ 0.35 and $r^{*}=0.89$ ). The frequencies are converted to nondimensionnal ones with the impeller rotation speed $N$ used as a reference frequency. The spectral analysis points out the most obvious signature: the signature of the rod motion. Close to the impeller, the dominant frequency is of course twice the impeller rotation rate (i.e., $f^{*}=2$ ).

These figures show that the dispersion of the experimental lines (3) versus angular position in the tank is moderate, except for very low frequencies. Similarly, the dispersion of the curves in the LES computation (6) is very limited, even at low frequencies. In Figure 13, several harmonics of the main frequency are observed, especially in the LES computation, namely, $f^{*}=2,4$, and 6 . The real experimental signal exhibits more dumped harmonics, for the harmonic $f^{*}=$ 6 is barely present in the real fluid. The peak close to $f^{*}=1$ in the simulation results is an artefact of an overestimated epitrochoidal motion superimposed to the rod rotation to 


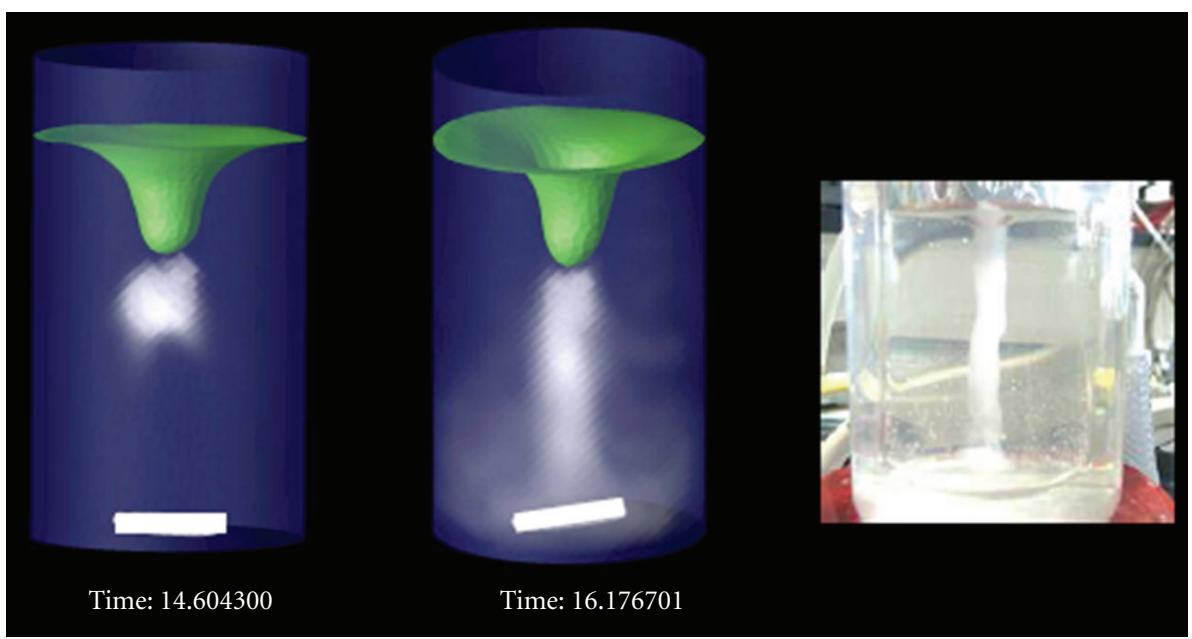

FIGURE 17: Tracer path-injection into the forced vortex.

mimic an off-axis precession of the centre of gravity of the rod. This motion has been observed for low height of liquid in the tank and postulated to exist when the tank is properly filled. The absence of such a $f^{*}=1$ peak in the experimental results shows that the real precession motion is more limited with nominal liquid height. Figure 13 points out also an unsatisfactory agreement between the highfrequency trends. The simulation seems to be overdissipating for the highest frequencies in several locations in the tank. This is probably due to a lack of resolution. The cutoff frequency in the calculation is a little too low, and as a consequence, the nonlinear convection scheme too much stabilizes the flow in those regions. However, this behaviour does not seem to affect the overall energy of the fluctuations: the agreement between experimental and computational lower frequency levels is fairly good.

Finally, we can conclude that here is globally a good agreement between LES and experiments, which validates the numerical simulations and its LES model. The LES hydrodynamic modelling can thus be applied to the precipitation process modelling.

3.5. Mean Velocity Fields. According to Nagata's theory, the mean tangential velocity increases linearly with the radius in the forced vortex zone (see Figure 15):

$$
0<r<r_{c}: \bar{u}_{t}=r \omega_{c}
$$

where $r_{c}$ is the radius of the boundary between the forced vortex and the free vortex.

The angular velocity of the fluid near the centre $\omega_{c}$ was found to be slightly lower than the agitator velocity $\omega_{a}$ : $\omega_{c} / \omega_{a}=93 \%$

In the free vortex zone, tangential velocity is inversely proportional to the radius:

$$
r_{c}<r<\frac{T}{2}: \bar{u}_{t} r^{0.6}=\text { constant }
$$

The computational values of the forced vortex radius are of the same order than those calculated with both Nagata et al.'s [25] and Le Lan and Angelino's [29] correlations. For instance, for an impeller Reynolds number of $710^{4}$, Table 3 presents the following different dimensionless radius $r_{c}^{*}=2 r_{c} / D$.

Figure 16 compares vortex profiles calculated at different moments with Nagata's theory. The computational-free surface is in good agreement with Nagata's relations:

$$
\begin{aligned}
& h=h_{a}+\frac{1}{2} \pi^{2}\left(R_{c}\right)^{2} D \operatorname{Fr}\left(\frac{r_{c}}{r}\right)^{2} \quad \text { for } 0 \leq r \leq r_{c}, \\
& h=h_{a}+\frac{1}{2} \pi^{2}\left(R_{c}\right)^{2} D \operatorname{Fr}\left[2-\left(\frac{r_{c}}{r}\right)^{2}\right] \\
& \text { for } r_{c} \leq r \leq \frac{T}{2},
\end{aligned}
$$

where Fr is the Froude number and $h_{a}$ the height between the bottom of the tank and the bottom of the vortex.

Using the results of the LES simulations, the radius of the boundary between the forced vortex and the free vortex can be accurately determined according to the operating conditions. This information is crucial to control the reagent feeding point.

3.6. Mixing Phenomena. The hydrodynamic modelling is used to enhance the mixing phenomena inside the vortex reactor. The injection of a tracer is simulated in order to visualize the preferential path followed by a fluid particle depending on the initial feed location. The computational simulations reproduce the previous experimental observations.

When the tracer is injected into the forced vortex, it remains confined inside until it reaches the stirrer; then it diffuses into the free vortex (see Figure 17).

On the contrary, when the passive tracer is supplied in the free vortex, the tracer is diluted into the whole volume of the reactor (see Figure 18). 


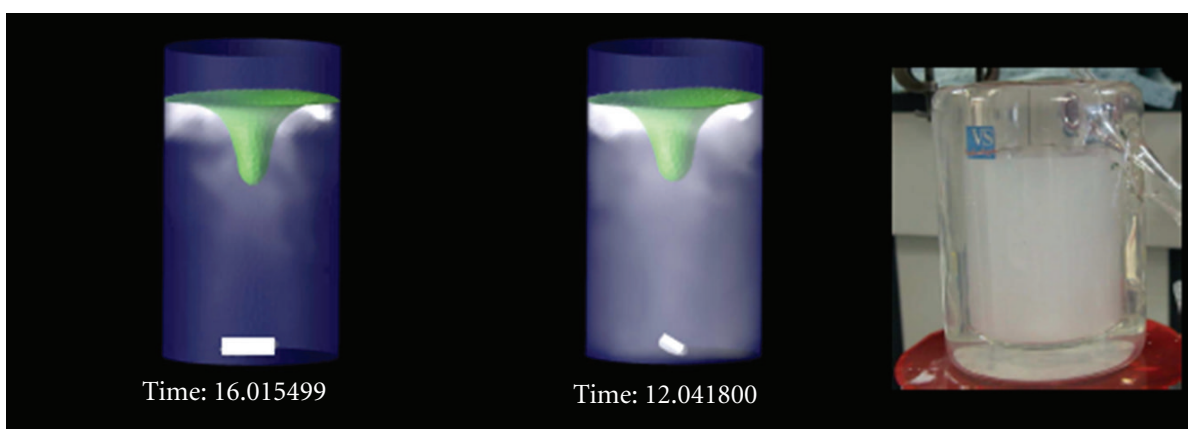

FIGURE 18: Tracer path-injection into the free vortex.

Mixing phenomena are completely different in both studied cases and influence highly precipitation mechanisms: nucleation, growth, and agglomeration processes. In the free vortex, the reagents injected are beforehand diluted into the surrounding fluid and precipitation takes place in the whole volume. On the contrary, in the forced vortex, inlet flows imprisoned in a very low volume remain concentrated so that high supersaturation gradients appear in the reactor. Thus, the free vortex enhances the growth process leading to the larger crystals, whereas the forced vortex characterised by high supersaturations enhances nucleation phenomena leading to smaller crystals. The supersaturation profile inside the precipitator is highly dependent on the reagent feeding position.

\section{Conclusions}

The LES approach using Trio_U code has been successfully applied to simulate with a high accuracy degree the flow in a vortex precipitator. The LES simulations allow the unsteady velocity and turbulence fields according to the agitator position to be calculated. The spectral analysis points out that the most significant frequencies are retrieved. Mixing phenomena are accurately described. Both numerical and experimental studies point out the major role of the flow pattern inside the precipitator. Indeed the mean crystal size can vary by a factor of 1.5 to 2 times only by modifying the reagent injection position. During the process precipitation, the position of the reagent feeding has to be controlled carefully; otherwise the precipitate properties vary. Using the results of the LES simulations, it is possible to get a good estimation of the radius of the forced vortex.

A global modelling of actinide precipitation processes is under development by combining this hydrodynamic model with kinetic laws in order to solve the population balance. Nucleation, crystal growth, and agglomeration kinetics are taken into account $[30,31]$. The computer simulation is an important tool for the design, the optimisation, and scale-up of new geometries, especially in nuclear environment where experiments are limited.

\section{Nomenclature}

$L_{43}$ : Mean volume particle diameter $(\mathrm{m})$

D: $\quad$ Magnetic rod length $(\mathrm{m})$ $h_{a}$ : Height between the bottom of the tank and the bottom of the vortex $(\mathrm{m})$

$H$ : Reactor height $(\mathrm{m})$

$N$ : $\quad$ Stirrer speed (rpm)

$r:$ Radius $(\mathrm{m})$

$r_{c}:$ Forced vortex radius $(\mathrm{m})$

$s, t$ : Fisrt and second eigenvalues of the anisotropy tensor $\left(\mathrm{m}^{2} . \mathrm{s}^{-1}\right)$

$t$ : $\quad$ Time (s);

$T: \quad$ Reactor diameter $(\mathrm{m})$

$u$ : Velocity vector, $\left(\mathrm{m} \cdot \mathrm{s}^{-1}\right)$

$V_{\theta}$ : Reference velocity, $\left(\mathrm{m} \mathrm{s}^{-1}\right)$

$z$ : Height m

$\omega:$ Angular velocity $\left(\mathrm{m} \cdot \mathrm{s}^{-1}\right)$

$v$ : Kinematic viscosity $\left(\mathrm{m}^{2} \cdot \mathrm{s}^{-1}\right)$

\section{Subscript}

*: Nondimensionalized variable.

\section{References}

[1] P. Auchapt and A. Ferlay, "Appareil à effet vortex pour la fabrication d'un procédé,” Patent FR 1556 996, 1981.

[2] T. Mahmud, J. N. Haque, K. J. Roberts, D. Rhodes, and D. Wilkinson, "Measurements and modelling of free-surface turbulent flows induced by a magnetic stirrer in an unbaffled stirred tank reactor," Chemical Engineering Science, vol. 64, no. 20, pp. 4197-4209, 2009.

[3] P. Armenante, C. C. Chou, and R. B. Hemrajani, "Comparison of experimental and numerical velocity distribution profiles in an unbaffled mixing vessel provided with a pitched-blade turbine," IChemE Symposium Series, vol. 136, pp. 349-356, 1994.

[4] M. Kagoshima and R. Mann, "Development of a networks-ofzones fluid mixing model for an unbaffled stirred vessel used for precipitation," Chemical Engineering Science, vol. 61, no. 9, pp. 2852-2863, 2006.

[5] S. Nagata, N. Yoshioka, and T. Yokoyama, "Studies on the power requirement of mixing impellers," Memoirs of the Faculty of Engineering, Kyoto University, vol. 17, pp. 175-185, 1955.

[6] H. Hartmann, J. J. Derksen, and H. E. A. van den Akker, "Macroinstability uncovered in a Rushton turbine stirred tank by means of LES," AIChE Journal, vol. 50, no. 10, pp. 2383-2393, 2004. 
[7] B. N. Murthy and J. B. Joshi, "Assessment of standard kElunate, RSM and LES turbulence models in a baffled stirred vessel agitated by various impeller designs," Chemical Engineering Science, vol. 63, no. 22, pp. 5468-5495, 2008.

[8] A. Delafosse, A. Line, J. Morchain, and P. Guiraud, "LES and URANS simulations of hydrodynamics in mixing tank: comparison to PIV experiments," Chemical Engineering Research and Design, vol. 86, no. 12, pp. 1322-1330, 2008.

[9] J. J. Derksen, M. S. Doelman, and H. E. A. van den Akker, "Three-dimensional LDA measurements in the impeller region of a turbulently stirred tank," Experiments in Fluids, vol. 27, no. 6, pp. 522-532, 1999.

[10] J. Derksen and H. E. A. van den Akker, "Large eddy simulations on the flow driven by a Rushton turbine," AIChE Journal, vol. 45, no. 2, pp. 209-221, 1999.

[11] R. Alcamo, G. Micale, F. Grisafi, A. Brucato, and M. Ciofalo, "Large-eddy simulation of turbulent flow in an unbaffled stirred tank driven by a Rushton turbine," Chemical Engineering Science, vol. 60, no. 8-9, pp. 2303-2316, 2005.

[12] S. L. Yeoh, G. Papadakis, and M. Yianneskis, "Determination of mixing time and degree of homogeneity in stirred vessels with large eddy simulation," Chemical Engineering Science, vol. 60, no. 8-9, pp. 2293-2302, 2005.

[13] H. S. Yoon, S. Balachandar, and M. Y. Ha, "Large eddy simulation of flow in an unbaffled stirred tank for different Reynolds numbers," Physics of Fluids, vol. 21, no. 8, Article ID 085102, 2009.

[14] B. Chapelet-Arab, L. Duvieubourg, G. Nowogrocki, F. Abraham, and S. Grandjean, "U(IV)/Ln(III) mixed site in polymetallic oxalato complexes. Part III: structure of $\mathrm{Na}\left[\mathrm{Yb}\left(\mathrm{C}_{2} \mathrm{O}_{4}\right)_{2}\left(\mathrm{H}_{2} \mathrm{O}\right)\right] \cdot 3 \mathrm{H}_{2} \mathrm{O}$ and the derived quadratic series $\left(\mathrm{NH}^{4+}\right)_{1-x}\left[\operatorname{Ln}_{1-x} \mathrm{U}_{x} \quad\left(\mathrm{C}_{2} \mathrm{O}_{4}\right)_{2}\left(\mathrm{H}_{2} \mathrm{O}\right)\right] \cdot(3+\mathrm{x}) \quad \mathrm{H}_{2} \mathrm{O}, \quad \mathrm{Ln}=\mathrm{Y}$, Pr-Sm, Gd, Tb," Journal of Solid State Chemistry, vol. 179, no. 12, pp. 4029-4036, 2006.

[15] R. Perry and C. Chilton, Chemical Engineer's Handbook, McGraw-Hill, New York, NY, USA, 5th edition, 1973.

[16] S. B. Pope, Turbulent Flows, Cambridge University Press, Cambridge, UK, 2000.

[17] Y. Benarafa, O. Cioni, F. Ducros, and P. Sagaut, "RANS/LES coupling for unsteady turbulent flow simulation at high Reynolds number on coarse meshes," Computer Methods in Applied Mechanics and Engineering, vol. 195, no. 23-24, pp. 2939-2960, 2006.

[18] C. Calvin and P. Emonot, "The Trio_U project: a parallel CFD 3-dimensional code," in Proceedings of the Scientific Computing in Object-Oriented Parallel Environments (ISCOPE '97), Y. Ishikawa, R. R. Oldehoeft, J. Reynders, and M. Tholburn, Eds., Lecture Notes in Computer Science, pp. 169-176, Springer, Marina del Rey, Calif, USA, December 1997.

[19] C. Calvin, O. Cueto, and P. Emonot, "An object-oriented approach to the design of fluid mechanics software," Mathematical Modelling and Numerical Analysis, vol. 36, no. 5, pp. 907-921, 2002.

[20] http://www-trio-u.cea.fr/.

[21] B. Mathieu, O. Lebaigue, and L. Tadrist, "Dynamic contact line model applied to single bubble growth," in Proceedings of the 41st European Two-Phase Flow Group Meeting, Trondheim, Norway, 2003.

[22] E. A. Fadlun, R. Verzicco, P. Orlandi, and J. Mohd-Yusof, "Combined immersed-boundary finite-difference methods for three-dimensional complex flow simulations," Journal of Computational Physics, vol. 161, no. 1, pp. 35-60, 2000.

[23] B. Mathieu, "A 3D parallel implementation of the fronttracking method for two-phase flows and moving bodies," in
Proceedings of the 177ème Session Société Hydrotechnique de France, Advances in the Modelling Methodologies of Two-Phase Flows, Lyon, France, November 2004.

[24] F. Nicoud and F. Ducros, "Subgrid-scale stress modelling based on the square of the velocity gradient tensor," Flow, Turbulence and Combustion, vol. 62, no. 3, pp. 183-200, 1999.

[25] S. Nagata, K. Yamamoto, and M. Ujhara, "Studies on the power requirement of mixing impellers," Memoirs of the Faculty of Engineering, Kyoto University, pp. 336-349, 1958.

[26] J. Jeong and F. Hussain, "On the identification of a vortex," Journal of Fluid Mechanics, vol. 285, pp. 69-94, 1995.

[27] R. Escudié and A. Liné, "Analysis of turbulence anisotropy in a mixing tank," Chemical Engineering Science, vol. 61, no. 9, pp. 2771-2779, 2006.

[28] N. Lamarque, B. Zoppé, O. Lebaigue, Y. Dolias, M. Bertrand, and F. Ducros, "Large-eddy simulation of the turbulent freesurface flow in an unbaffled stirred tank reactor," Chemical Engineering Science, vol. 65, no. 15, pp. 4307-4322, 2010.

[29] A. Le Lan and H. Angelino, "Etude du vortex dans les cuves agitées," Chemical Engineering Science, vol. 27, no. 11, pp. 1969-1978, 1972.

[30] M. Bertrand-Andrieu, E. Plasari, and P. Baron, "Determination of nucleation and crystal growth kinetics in hostile environment-application to the tetravalent uranium oxalate $\mathrm{U}\left(\mathrm{C}_{2} \mathrm{O}_{4}\right)_{2} \cdot 6 \mathrm{H}_{2} \mathrm{O}$," Canadian Journal of Chemical Engineering, vol. 82, no. 5, pp. 930-938, 2004.

[31] S. Lalleman, M. Bertrand, and E. Plasari, "Physical simulation of precipitation of radioactive element oxalates by using the harmless neodymium oxalate for studying the agglomeration phenomena," Journal of Crystal Growth, vol. 342, no. 1, pp. 4249, 2012. 

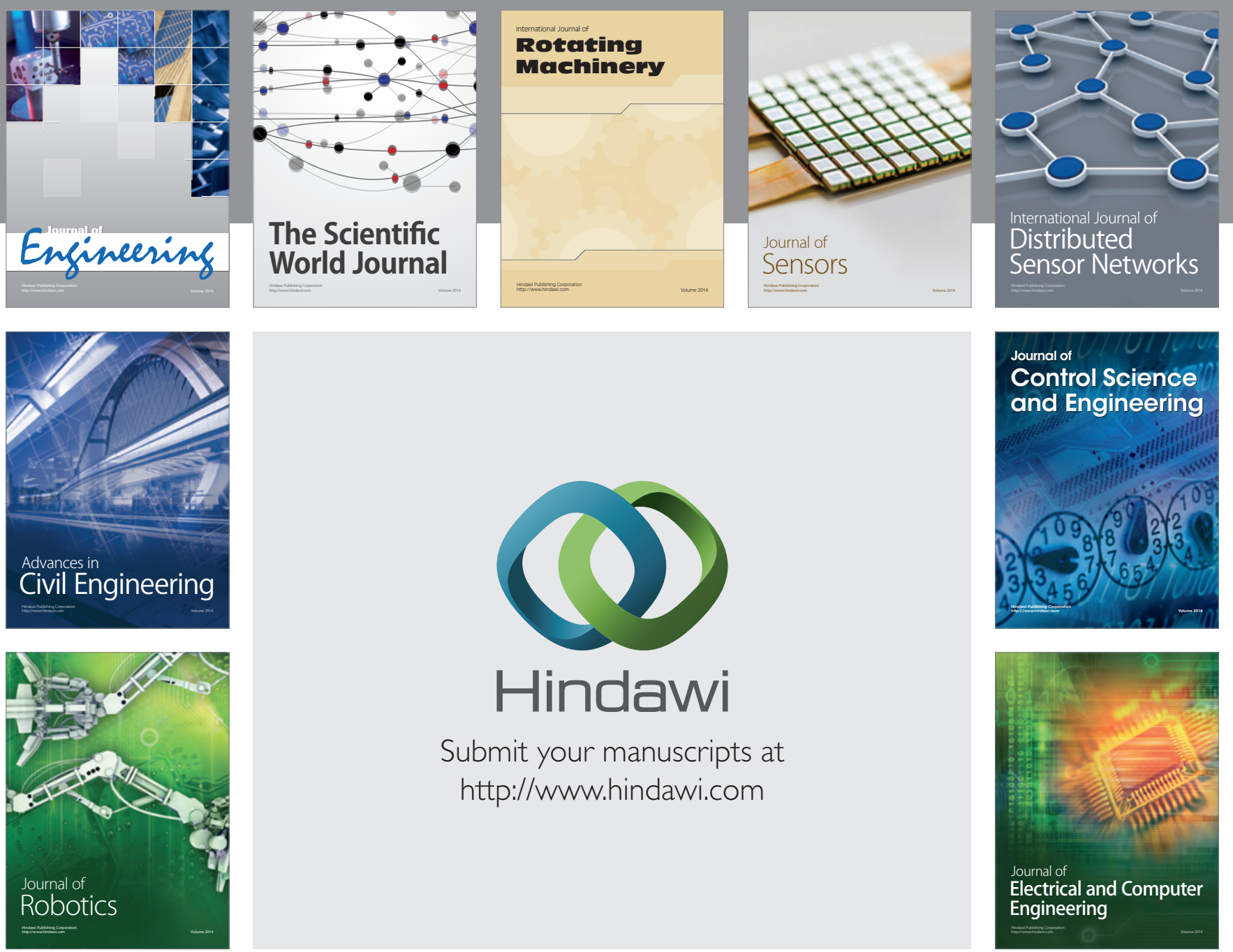

Submit your manuscripts at

http://www.hindawi.com
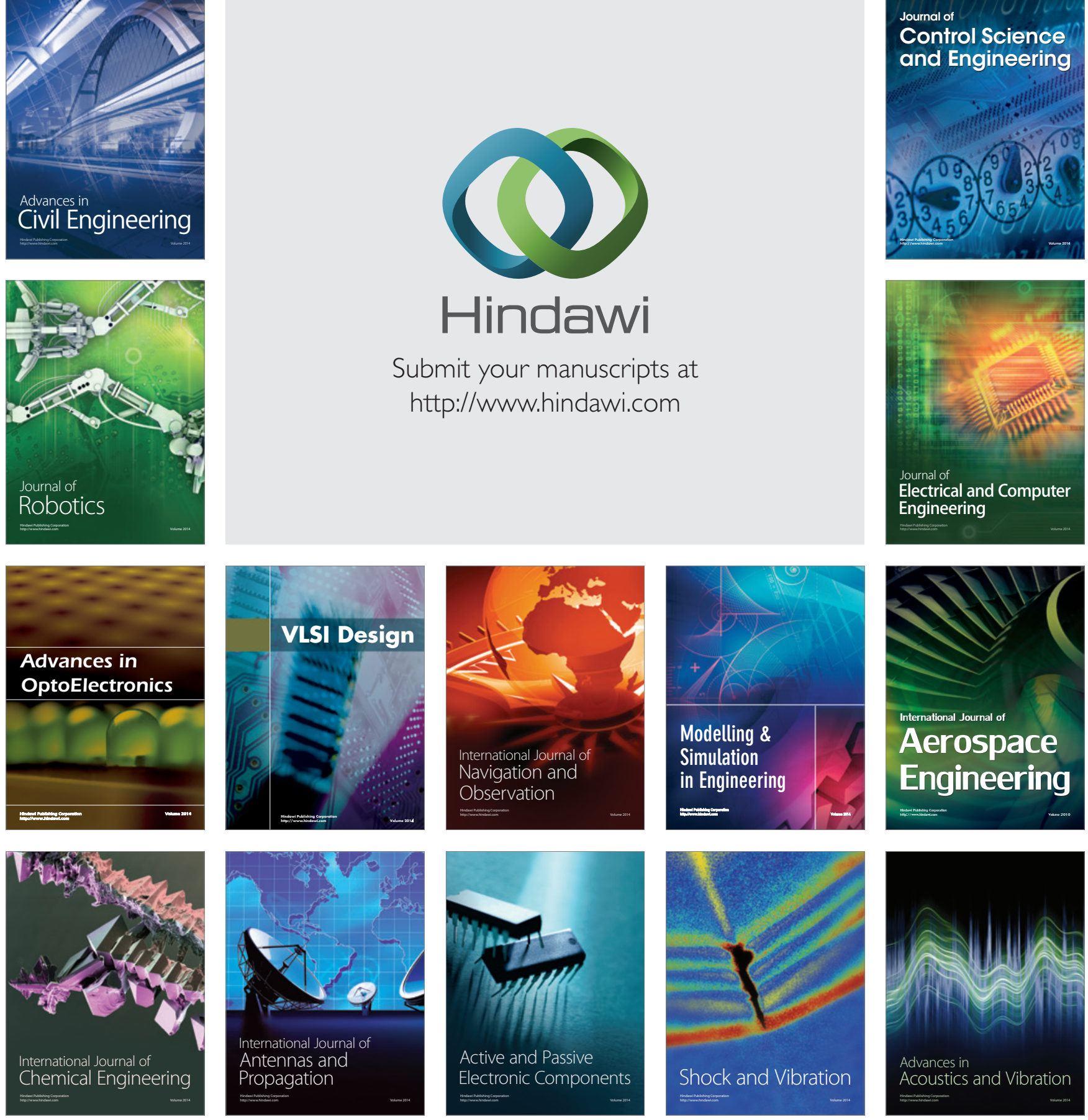